\title{
A 40-year mesoscale gridded fire weather climatology for Victoria - an overview
}

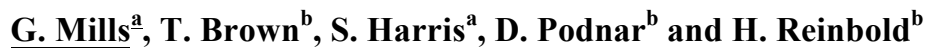 \\ ${ }^{a}$ School of Geography and Environmental Science, Monash University, Clayton, Victoria \\ ${ }^{b}$ Desert Research Institute, University of Nevada, Reno \\ Emailgam4582@gmail.com
}

\begin{abstract}
A homogeneous 40-year (1972-2013), hourly interval, 4-km grid climate data-set for Victoria has been generated using a combination of mesoscale modelling, global reanalysis data, surface observations, and historic observed rainfall and temperature analyses. The primary purpose of this data set is for fire management planning.
\end{abstract}

The numerical modelling approach to generate such a data set avoids the issues of inhomogeneity in both time and space of the observational data. The inhomogeneities in time include changes in observation network density and changes in reporting frequency. The latter is particularly evident during the period of transition from mostly manual synoptic (3-hourly at best) observations to hourly or half-hourly Automatic Weather Station observations that occurred during the 1990's. Spatial inhomogeneity is particularly important from a fire weather perspective due to the lack of observations in areas (e.g. forests, steep terrain) critical to fire management.

The Weather and Research Forecasting (WRF) mesoscale model is used to generate these data. The model is initialised from global reanalysis fields, with three internal nests $(36 \mathrm{~km}, 12 \mathrm{~km}$ and $4 \mathrm{~km})$. The outer mesh is nested within 6-hourly global reanalyses. Hourly near-surface forecast fields are combined with Drought Factor fields calculated from the Australian Water Availability Project rainfall and temperature analyses to generate fields of hourly fire danger indices for each hour of the 40 -year period. As with any numerical model, there is the potential for both bias errors and also episodic (synoptic) errors to occur. We are assessing these errors and developing methods by which they may be ameliorated.

Outputs provide an almost limitless opportunity for hitherto unavailable analyses - fields of percentiles of Forest Fire Danger Index values, analysis of periods exceeding thresholds at any location, inter-annual and regional variations of fire season characteristics, analysis of prescribed burning windows, of atmospheric dispersion climatologies, of various atmospheric stability measures that might affect fire behaviour, and to assess climatologies of more esoteric mesoscale weather events, such as mountain waves or dry slots, that may affect fire behaviour. The hourly mesoscale data also provide a hitherto unavailable long-period homogeneous data set with which to drive fire spread models, and to consider event-based impacts as well as long-term regional and local-scale bushfire risk..

Keywords: Fire weather climatology, Mesoscale modelling, Victoria 


\section{INTRODUCTION}

There is a need for a detailed understanding of the climatology of fire weather across the landscape if strategic decisions to ameliorate the sometimes-extreme impacts of bushfires on the socio-economic wellbeing of the community are to be based on sound scientific evidence, and if variability and trends in this climatology are to be correctly interpreted. This paper describes the methodology by which a 1972-present high temporal- and spatial-resolution climatology of Victoria's fire weather is being developed. The climatology is intended to combine hourly values of meteorological variables on a regular, high spatial resolution, grid over Victoria with drought factors based on the Australian Water Availability Project (AWAP) rainfall and temperature analyses (Jones et al. 2009) to generate hourly gridded fields of Forest Fire Danger Index (FFDI).

There are some considerable barriers to basing such a climatology on long-term meteorological observations, as shown by the relatively low number of reliable, long term observation records available for such analyses (see Lucas et al 2007). These issues with the Bureau of Meteorology observing network can perhaps be broadly categorized into inhomogeneities in time, and inhomogeneities in space.

Over time there have been steady changes in observing networks, observing practice, and instrumentation. Figure 1 shows the Bureau's observing network over Victoria in 1972 and in 2008 . There are clearly many more stations in recent years. Further, in the early years the reporting frequency was at best 3-hourly, and at a significant number of stations reports were only at $9 \mathrm{am}$ and $3 \mathrm{pm}$. In addition, stations opened, closed, or were moved during this period. A significant change in reporting frequency and in observing practice occurred from the early 1990's, when Automatic Weather Stations (AWS) gradually replaced the manual observations. This had several benefits, including much more frequent reporting and of not having to locate the instrumentation at a place where personnel needed to be available at each observation time. In addition, and enormously important from a fire weather perspective, anemometers were universal with these AWS, and so quantitative rather than estimated wind speeds were now the norm rather than only being available at a few stations. The implication of these inhomogeneities in wind speed estimation/measurement for fire weather calculations is shown in Lucas (2010).

Inhomogeneities in space of the observing network also have significant implications for fire weather applications. The bulk of the observations are based near population centres, and so do not necessarily reflect the conditions in the forests where the bulk of major bushfires occur, and which are concentrated in the slopes and valleys of the ranges through central and eastern Victoria.

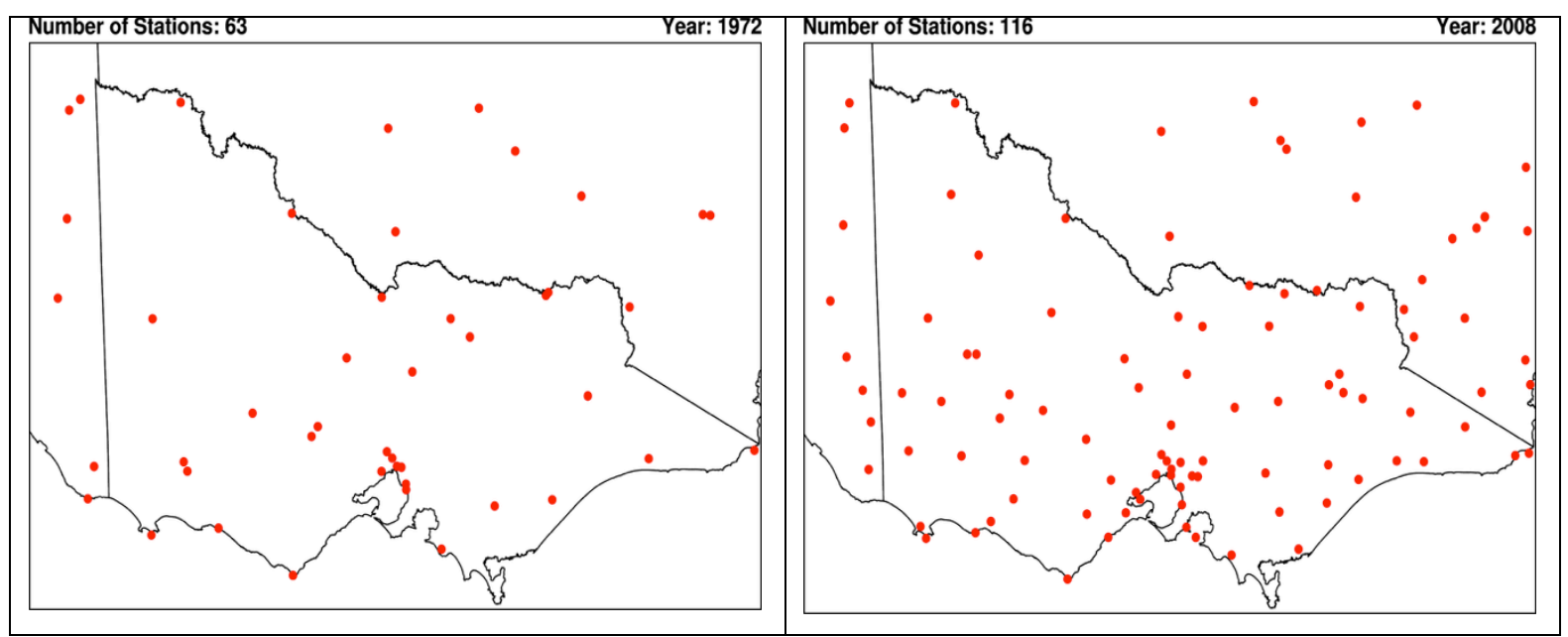

Figure 1. Observing network over Victoria in 1972 (left) and 2008 (right).

It is logistically possible to spatially interpolate between observing stations to obtain a regular grid of data using distance-weighted averages, or more complex schemes, and this has long been used in Numerical Weather Prediction (NWP) systems. However, ensuring physical consistency when interpolating across regions of varying elevation or land surface type requires additional statistical assumptions that rapidly lead to excessive complication. Further, the fact that observations are not available at hourly intervals throughout the period desired also makes some form of interpolation in time necessary if hourly fields are desired, and this also adds complication as any assumptions regarding diurnal cycles of variables would generally ignore differences through the synoptic weather cycle. 
Numerical weather prediction models can provide data sets on a regular grid that are physically constrained by the models's equations of motion and thermodynamics, and which include topography appropriate to the model's resolution.

Operational NWP model outputs, while archived by most national weather services, suffer by the fact that these models are upgraded every few years, and so have major inhomogeneities if they are to be used for climatological studies.

The emergence of global reanalysis data sets such as the NCEP/NCAR, (Kalnay et al. 1996), NCEP/DOE II (Kanamitsu et al 2002), or ERA-Interim (Dee et al 2011) reanalysis data sets are homogeneous as far as resolution and analysis technique are concerned, although this homogeneity is unavoidably affected by changes in observation networks, particularly prior to the satellite era. These reanalyses are generally available at 6-hourly intervals, and have grid spacings of between 1.5 and 2.5 degrees latitude/longitude. This temporal and spatial resolution does limit their use for fire weather applications due to the mesoscale nature of many of the highest impact fire weather events.

Reanalyses can, though, be used as initial and boundary conditions for mesoscale NWP model integrations, with multiple nests if desired to achieve high spatial detail in the inner nests. This option has been chosen for the current project.

This paper will describe the model configuration, running strategy, and quality control/assessment procedures we are using in developing the data set, and will describe the types of analyses that we intend to perform with the completed data set, along with suggestions for using these data in future research and operational based projects.

\section{MODELLING CONFIGURATION}

The mesoscale model used is the Weather Research and Forecasting (WRF) model described by Skamarock et al. (2008). It is a well-supported and widely used non-hydrostatic model that includes a wide range of choices of physical parameterization schemes. Three integration domains are used in our configuration (Fig. 2) with grid spacings of $36 \mathrm{~km}$ (outer mesh), $12 \mathrm{~km}$ (middle mesh), and $4 \mathrm{~km}$ (inner mesh). Each nest has 33 vertical model levels. Initial state and lateral boundary conditions for the outer mesh are provided by 6hourly interval global reanalyses. Choices of physical parameterization packages selected are listed in Table 1 .

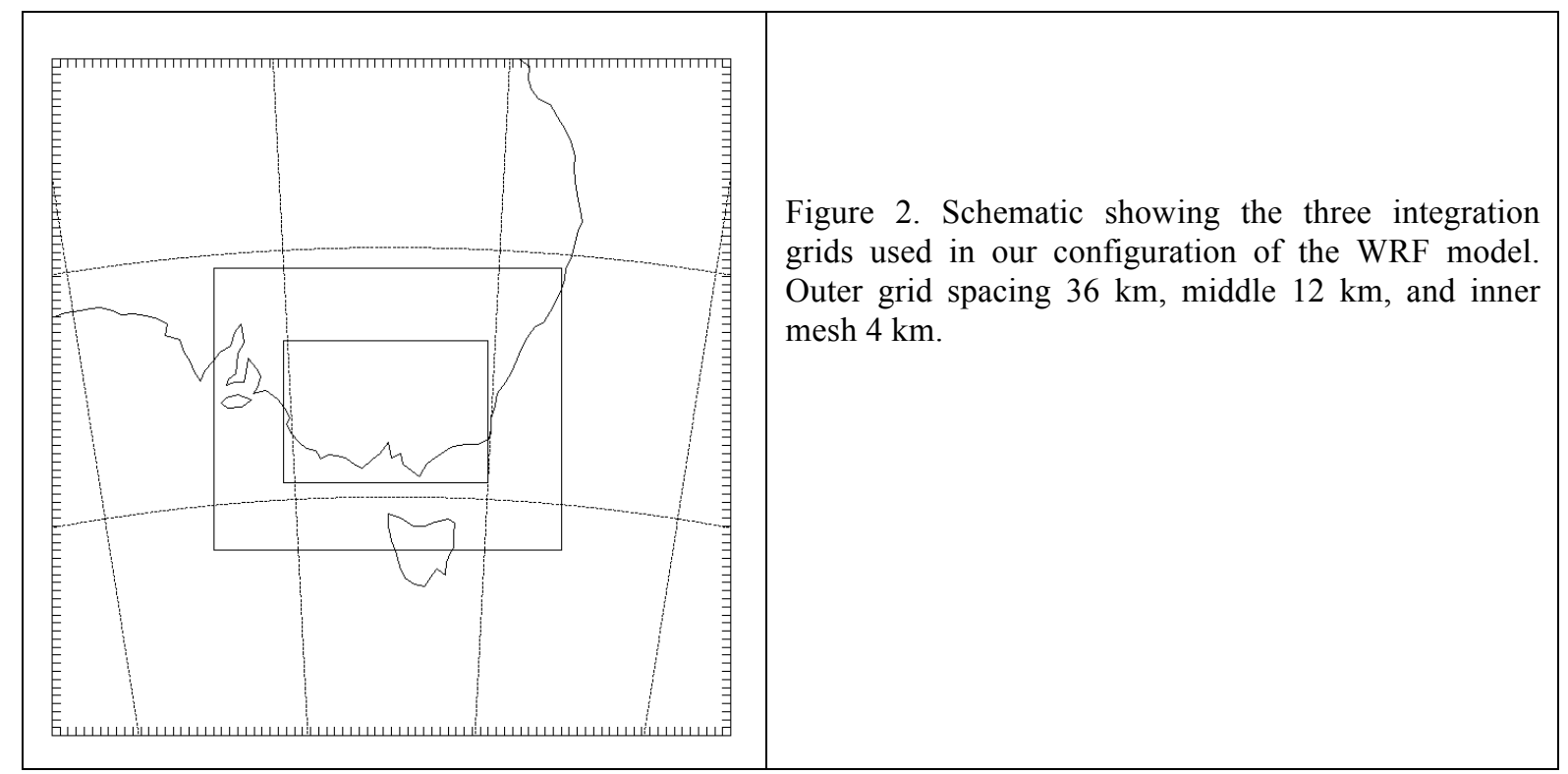

The best running strategy for using the WRF model to produce an hourly 3-dimensional data set of wind, temperature, and humidity is not at all apparent. There are logistical and data set quality benefits in performing longer (multi-day) rather than shorter (1-2 day) integrations as it is desirable not to have too many discontinuities at the commencement of each new integration due to the need for the inner mesh to "spin up" from the smooth global reanalysis fields. One would intuitively expect that the model solution would drift somewhat from reality with time, although the use of analysis lateral boundary conditions rather than the forecast conditions used in operational forecast models should reduce this effect somewhat. After 
Mills et al. A 40-year mesoscale gridded fire weather climatology for Victoria

considerable testing, we have chosen to generate the data using 15-day integrations, but with the first day of each integration treated as a spin-up period and thus discarded. Therefore days 2-15 of each integration become Days 1-14 of each two-week data set period. Evidence supporting the quality of the data produced is given in the next section.

The choice of reanalysis to use for initial state and lateral boundary conditions is somewhat open. It seems, a priori, that higher rather than lower resolution is preferable, and with clearly a wider range of options post 1979 than before. Testing continue to determine the sensitivity of our outputs to choice of global input fields.

Table 1. List of physical parameterisations used in this WRF configuration.

Microphysics: Thompson et al. scheme: A new scheme with ice, snow and graupel processes suitable for high-resolution simulations (8).

Longwave Radiation: RRTM scheme: Rapid Radiative Transfer Model. An accurate scheme using look-up tables for efficiency; it accounts for multiple bands, trace gases, and microphysics species.

Shortwave Radiation: Goddard shortwave: Two-stream multi-band scheme with ozone from climatology and cloud effects.

Land Surface: Noah Land Surface Model: Unified NCEP/NCAR/AFWA scheme with soil temperature and moisture in four layers, fractional snow cover and frozen soil physics.

Planetary Boundary layer: Yonsei University scheme: Non-local-K scheme with explicit entrainment layer and parabolic K profile in unstable mixed layer.

Cumulus Parameterization: Kain-Fritsch scheme: Deep and shallow convection sub-grid scheme using a mass flux approach with downdrafts and CAPE removal time scale.

Diffusion Option: Simple diffusion: Gradients are simply taken along coordinate surfaces.

K Option: 2d Deformation: $\mathrm{K}$ for horizontal diffusion is diagnosed from just horizontal deformation. The vertical diffusion is done by the PBL scheme.

\section{Quality control and meteorological Integrity}

The quality of the data set can be measured in a number of ways, and these are being conducted on an ongoing basis as the model grids are generated. Simple measures such as Root-Mean-Square (RMS) error from observations are fundamental, but given the running strategy it is necessary that there is no trend in time from days 1-14 of these quantities, and that there is no trend in time of variance in the grid variables (i.e. no trends in noisiness), and while some discontinuity between these evaluation metrics must be expected across from the last hour of one integration to the first hour of the next, these would hopefully reflect meteorological, rather than, computational differences. Further, the meteorological integrity of the data should be consistent through the integration, with significant fire weather events such as frontal passages well represented, and no periods of deviation from synoptic reality should occur.

The first test of this configuration was for the summer period 1 November $2008-20$ March 2009. This comprised ten 15-day integrations. In order to assess any changes in quality or character of the data with length of the integration, for each hour of the 15-member two-week integration the RMSE for 10-m wind speed and 2-m temperature and relative humidity against approximately 115 observation stations was computed, together with the grid area variance of these quantities. An example for wind speed is shown in Fig. 3. There are several interesting features of these plots. First, there is considerable diurnal variation. Second, the fact that the peaks of each diurnal cycle vary in amplitude indicates that 15 members is insufficient for synoptic variations to be averaged out. However, the third point is the most important in this preliminary assessment context - there is essentially no trend in either metric through the integration period.

Figure 4 shows the field variance of wind speed for each hour of each integration. These individual timeseries show greater influence of synoptic variations, but pleasingly show relatively little discontinuity across integration periods, and when field variance is high at the end of one cycle (eg the third panel on the top row) it also is high on the first cycle of the next integration. Further, when variance is low at the end of one cycle, it tends also to be low at the start of the next (e.g. the two panels in the bottom row). Note that there are changes in ordinate scale in the individual panels of Fig. 4. 


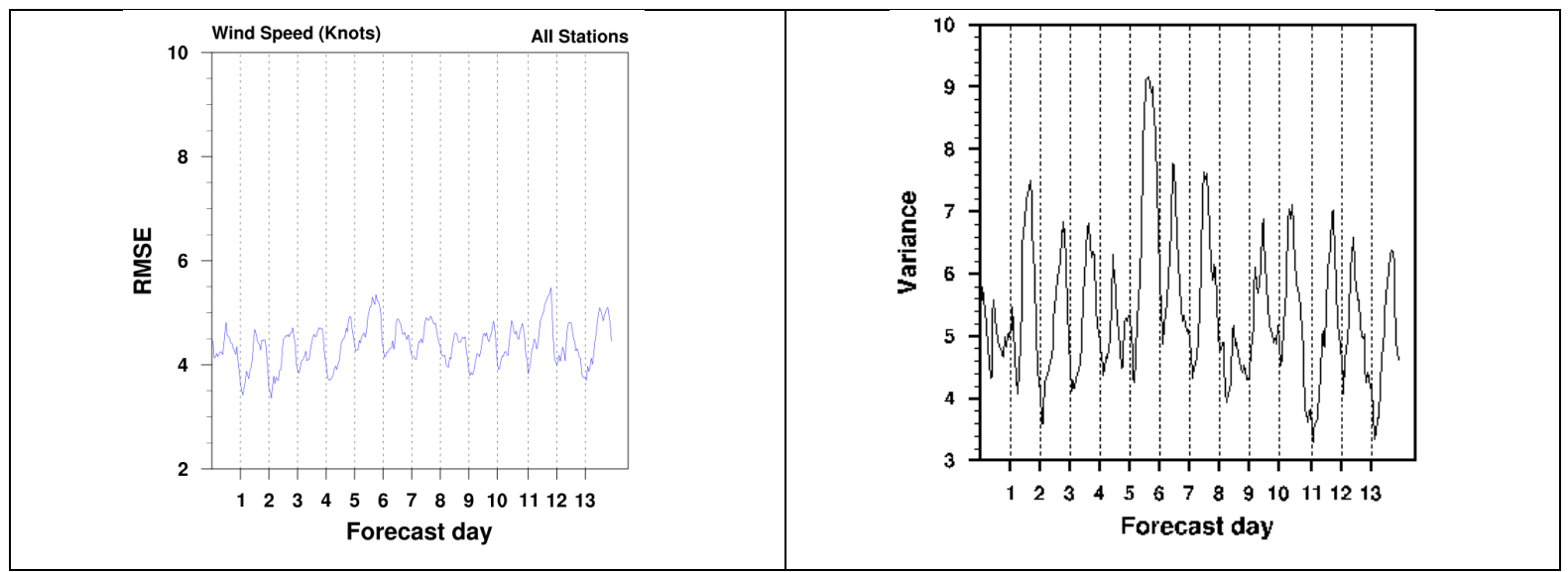

Figure 3. RMSE for 10-m wind speed (knots) for each hour of the 15 integration periods (left), and grid variance of $10-\mathrm{m}$ wind speed (right). The first spin-up day of each integration period is not shown.

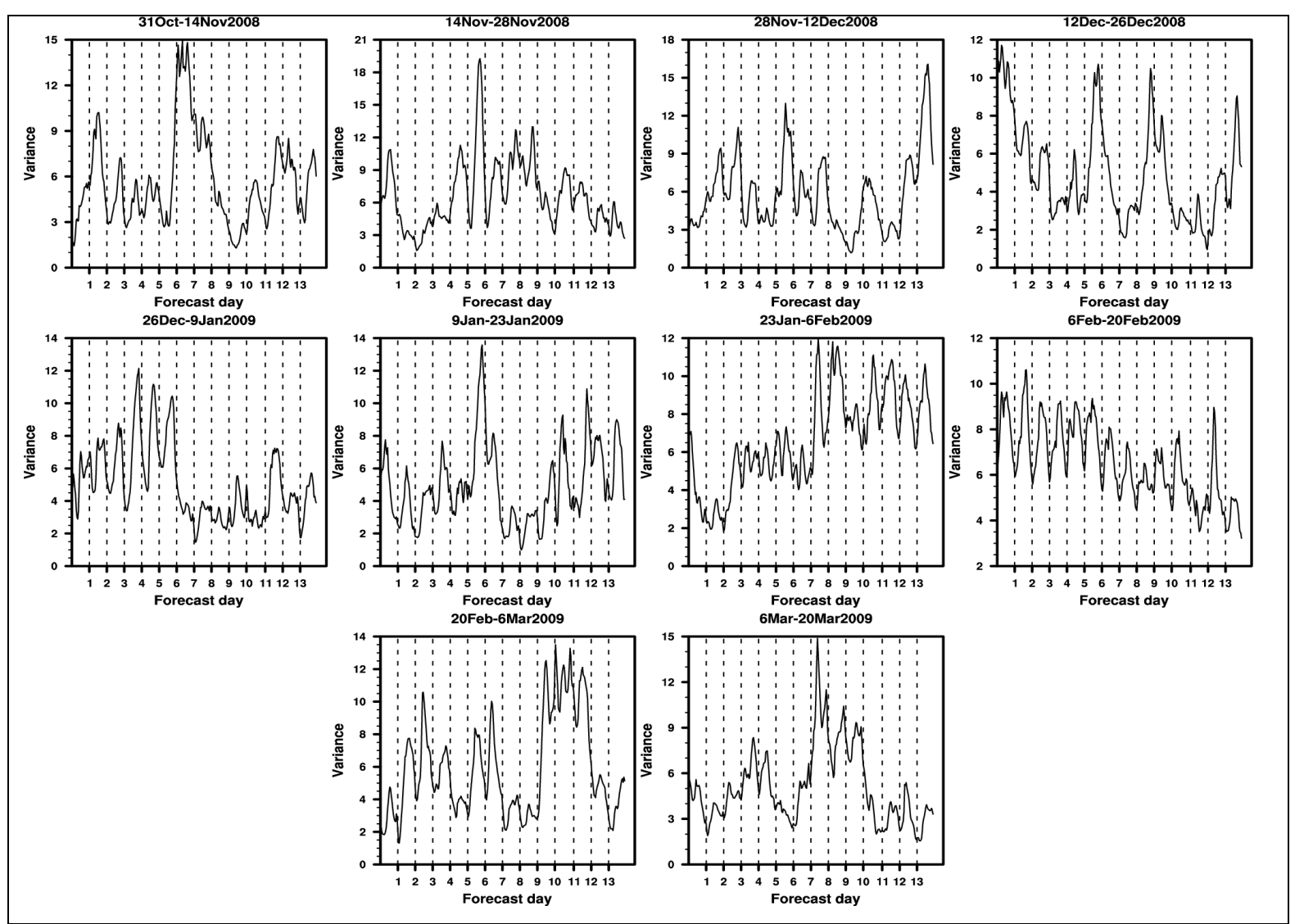

Figure 4. Plots of field variance of the model grid wind speed at each hour for each two-week integration period of the summer of 2008-2009.

In addition, during the early phases of the development of the data set each individual hourly field is being examined subjectively to ensure meteorological integrity. Figures 5 and 6 show an example of the WRF fields for an individual fire weather event - Black Saturday 2009, when massive fires led to major loss of life and property in Victoria (Teague et al. 2010). Figure 5 shows the temperature and relative humidity at 0300 UTC when the cool change was just inland from the coastline in western Victoria, and temperatures above $42^{\circ} \mathrm{C}$ and relative humidities below $15 \%$ are simulated over much of western and central Victoria ahead of the cool change. Figure 6 shows the wind direction and speed later the same day, just after the cool change had passed Melbourne. The timing and the structure of the change is excellent, with the faster movement of the southern portion of the change, and the areas of stronger post-change winds, well represented. 
It must be noted that the fields presented in Figs. 5 and 6 are from the early part of a two-week integration, and one might wonder if similar accuracy of simulation could be achieved later in an integration. On-going evaluation of this will continue, but an encouraging example is for another cool change event, that of the cool change of 20 January 2009. While this change was not as severe as that of Black Saturday, it was still an abrupt change of wind speed, direction, temperature and relative humidity. The change was observed at Melbourne Airport at 0335 UTC (1435 local time), and the WRF simulations showed the change to move over that site between 0300 and 0400 UTC (not shown). This was from the integration initialized on 9 January 2009, indicating that the combination of analysis lateral boundary conditions and WRF model can provide realistic simulations late in the integration period.

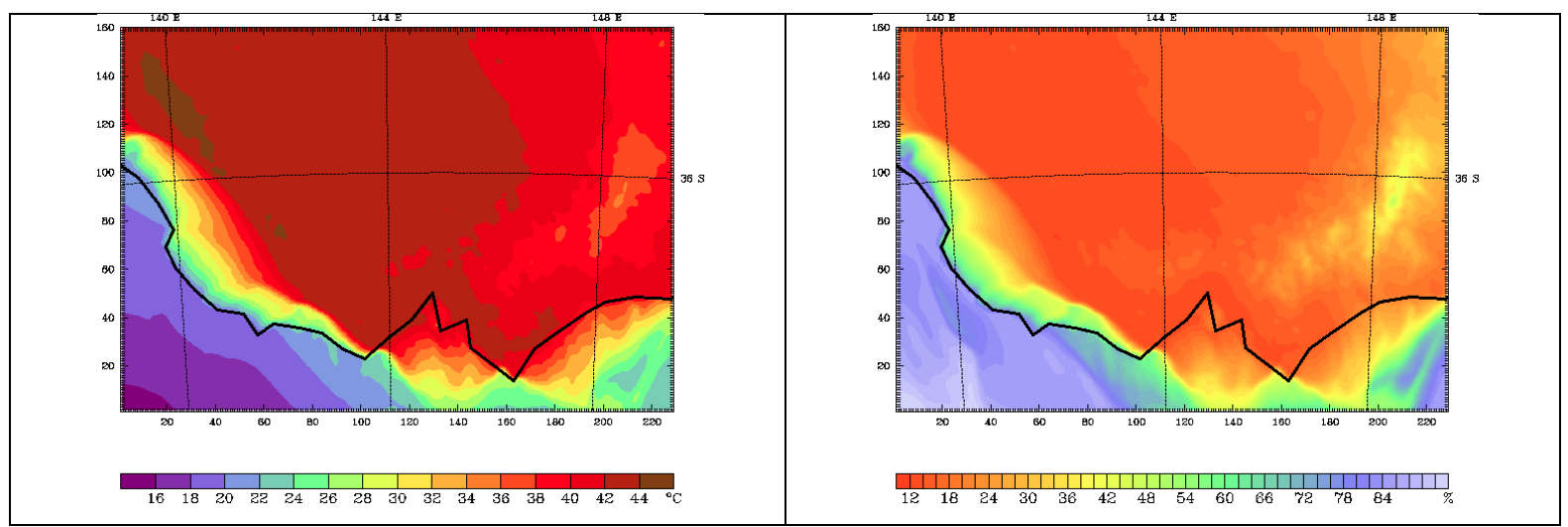

Figure 5. Simulated temperature $\left({ }^{\circ} \mathrm{C}\right.$, left) and relative humidity (\%, right) at 0300 UTC 7 February 2009 from the WRF integration.

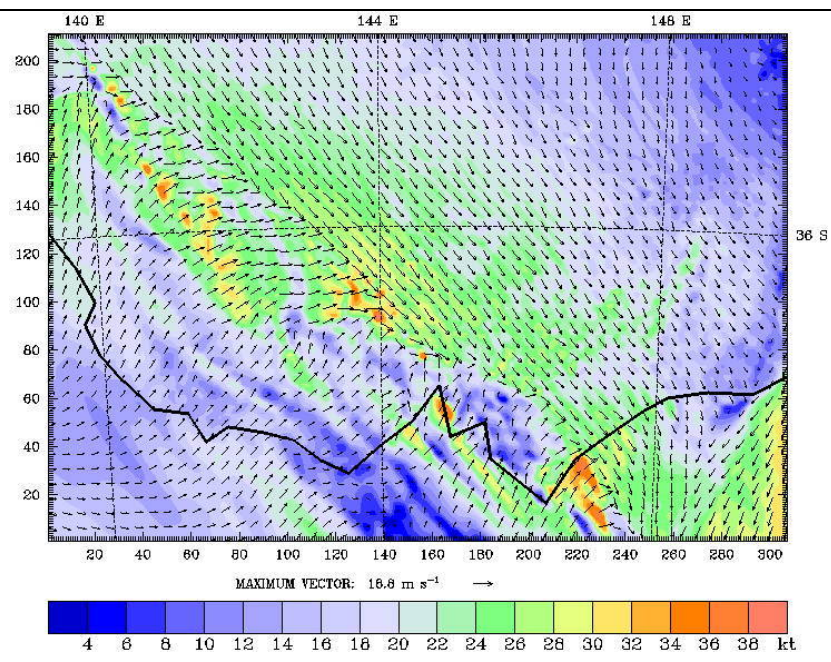

Figure 6. Simulated wind speed and direction at 0700 UTC 7 February 2009 from the WRF integration.

\section{APPLICATIONS}

There are a number of intended applications of this data set. These include

- Providing a high-resolution temporally and spatially complete record of temperature, humidity, wind, precipitation, drought and fire danger;

- Allowing for analyses at local through regional through state scales;

- Showing interannual and decadal variability for the elements produced, as well as climate trend;

- Quantitatively linking climate variability and trend to impacts from fire, heat waves, drought, etc;

- Providing a historical baseline that can be used in comparison studies with downscaled regional or place-based future climate data;

- Serving as input data for decision-support tools to obtain historic baselines;

- Providing quantitative climate values to help test agency strategies and predict ecological outcomes;

- Helping determine if assumptions that go into policy and operations are supported by what is known about the climate record; 
Mills et al. A 40-year mesoscale gridded fire weather climatology for Victoria

- Helping determine the extent that fire management responses have been "driven" by climate versus other forcing factors (e.g., political, economic, public perceptions);

- Estimating climate related bushfire risk;

- Estimating number of days suitable for planned burning;

- Input into the allocation of fire management resources - including planned burning;

- Bushfire case study analysis, refinement and improvement of burning prescriptions;

- Development of climate envelopes for vegetation communities;

- Development of weather predictions for "fire use" decision making, and future bushfire climate predictions for strategic planning;

- Providing hourly high-resolution input for fire spread models, (eg Phoenix (Tolhurst et al. 2008).

While the FFDI climatology uses the surface fields from the model, and this was the initial priority of this project, the fact that the WRF model outputs hourly 3-dimensional fields of all atmospheric variables means that there is the opportunity to assess the climatology of above-surface weather on fire activity that have never been possible at this scale over Victoria before. These studies include the effect of atmospheric stability on fire behavior using indices such as those described by Mills and McCaw (2010), and the potential to perform climatological assessments of foehn/mountain wave events such as those described by Sharples et al. (2010) and Badlan et al. (2012) or other mesoscale systems that are difficult to analyse climatologically from the observational record.

\section{CONCLUSIONS}

This data set is being produced at the time of writing of this paper, and is intended to be available for analysis by the second quarter of 2014. Components of the project not described in this paper, but which will enhance the utility of the data for many applications include an error correction component that will statistically adjust the grid field to ameliorate any biases or random errors that may be found, and a user interface that will provide access to a number of diagnostic and climatological analyses

\section{REFERENCES}

Badlan, R.L., Lane, T.P., Mills, G.A., and Caine, S., 2012. Mesoscale modeling of two "drying events": governing processes and implications for fire danger. Aust. Meteor. Oceanog. J. 62, 143-156.

Dee, D. P., and 35 co-authors, 2011: The ERA-Interim reanalysis: Configuration and performance of the data assimilation system. Quart. J. R. Meteorol. Soc., 137, 553-597.

Jones, D., Wang, W., and Fawcett, R., 2009. A high quality spatial historical data set for Australia. Aust. Meteor. Oceanog. J. 58, 233-248.

Kalnay E and co-authors, 1996. The NCEP/NCAR 40-year reanalysis project. Bull. Am. Met. Soc., 77, 437471.

Kanamitsu, M., Ebisuzaki, W., Woollen, J., Yang Shi-Keng, Hnilo, J.J., Fiorino, M., Potter,G.L., 2002: NCEP-DOE AMIP-II Reanalysis (R-2). Bull. Amer. Meteor. Soc., 83, 1631-1643.

Lucas, C., 2010. On developing a historical fire weather data-set for Australia. Aust. Meteor. Oceanog. J. 60, $1-14$.

Lucas, C., Hennessey, K., Mills, G., and Bathols, J., 2007. Bushfire weather in southeast Australia: recent trends and projected climate change impacts. Consultancy Report prepared for the Climate Institute of Australia. Bushfire Cooperative Research Centre, 81pp.

Mills, G.A., and L.McCaw 2010. Atmospheric Stability Environments and Fire Weather in Australia extending the Haines Index. CAWCR Technical Report No20, 158pp

Sharples, J.J., McRae, R.H.D., Mills, G.A., and Weber, R.O., 2010. Foehn-like winds and elevated fire danger conditions in southeastern Australia. J. Appl. Met. and Climat. 49, 1067-1095.

Skamarock, W., Klemp, J., Dudhia, J., Gill, D., Barker, D., Duda, M., Wang, W. \& Powers, J., 2008. 'A Description of the Advanced Research WRF Version 3', NCAR Technical Note NCAR/TN-475+STR.

Teague, B., Mcleod, R., and Pascoe, S., 2010. 2009 Victorian Bushfires Royal Commission Report. Government Printer for the State of Victorai, Melbourne, Australia.

Tolhurst., K.G., Shields, B.J. and Chong, D.M., 2008. PHOENIX: development and application of a bushfire risk management tool. Australian Journal of Emergency Management 23, 47-54. 